чтобы быть предельно уверенным в сохранности своего имущества, нужно присмотреться к самой оптимальной стоимости.

После стоимости одним из немаловажных критериев будет являться схема доставки грузов. Ведь о добросовестной работе будет говорить и тот факт, что менеджеры просчитают для вас наиболее оптимальный маршрут. В частности, не всегда выгодно доставлять товар с помощью одного вида транспорта. Иногда рациональнее вначале, например, отправить товар по железной дороге, а затем - морем. Как известно, у любой транспортной компании существуют свои наработанные схемы, по которым доставляют грузы. Лучше всего будет выбрать грузоперевозчики, у которого в схеме сочетается безопасности с эффективностью. [5].

Еще одним важным критерием является опыт работы в данной сфере. Компания, компания на протяжении многих лет пользуется доверием со стороны клиентов, скорее всего предоставит вам свои услуги без задержек и иных проблем, которые могут произойти. А чтобы понять, сможет ли компания заняться перевозкой именно того товара, который вам нужно перевезти, нужно узнать, какими именно перевозками занимается фирма, куда вы обращаетесь, ведь все они могут быть абсолютно разными.

Одни перевозят грузы внутри нашей страны, а также и за рубеж. Другие же компании имеют более узкое направление в своей деятельности и не смогут оправдать ваши надежды и осуществить ваши планы. Так как они могут заниматься перевозкой определенных видов грузов, но уже знать все нюансы, которые учитываются при транспортировке. И в добавок к вышесказанному если перевозимый товар очень ценный, то нужно выяснить берет ли на себя компания ответственность за транспортировку вашего имущества.

В итоге хочется отметить то что если владелец груза будет учитывать все критерии, которые упомянуты выше, то он сможет без особого труда и без опасений определиться с выбором компании, которой он сможет доверить отправление в другое место свой груз.

$$
* * *
$$

1. Воронов В.И. Международная логистика (Электронный ресурс). Вестник университета (Государственный университет управления). 2014. с.700.

2. Логистика и управление цепями поставок. Теория и практика. Основы логистики. Аникин Б.А.; Родкина Т.А.; Волочиенко В.А.; Заичкин Н.И.; Межевов А.Д.; Федоров Л.С.; Вайн В.М.; Воронов В.И.; Водянова В.В.; Гапонова М.А.; Ермаков И.А.; Ефимова В.В.; Кравченко М.В.; Серова С.Ю.; Серышев Р.В.; Филиппов Е.Е.; Пузанова И.А.; Учирова М.Ю.; Рудая И.Л. Учебное пособие / Москва, 2014.

3. Воронов В.И., Воронов А.В., Ермаков А.А. Внешнеторговая статистика в развитии международного маркетинга и логистики. Маркетинг. 2014. № 1 (134). С. 90-96.

4. Электронный ресурс, режим доступа: http://fcalogistics.ru/selection-criteria-of-the-carrier - свободный.

5. Электронный ресурс, режим доступа: https://avtonovostidnya.ru/dorogi/vybor-nadezhnoy-transportnoykompanii-glavnye-kriterii - свободный.

\title{
Исаченко И.П. \\ Исследование состояния и развития коммуникаций в сфере логистики снабжения
}

\author{
Государственный университет управления
}

(Россия, Москва)

doi: $10.18411 / l j-31-10-2017-29$

idsp: 000001:lj-31-10-2017-29

\section{Аннотация}

Основное внимание в работе автор акцентирует на проблему коммуникаций в логистике снабжения между поставщиками и предприятием, а также приведено возможное решение для преодоления данной проблемы.

Ключевые слова: закупочная логистика, проблемы логистики, деловая коммуникация, информация, поставщик. 
В современное время, как показывает статистика маркетинга и логистики на международном и национальных уровнях, практически ни одна организация не может полностью обеспечивать сама себя всеми материалами и ресурсами для продолжения своей производственной, коммерческой, предпринимательской деятельности[1,2]. Поэтому логистика закупок играет важную и неотъемлемую часть в жизни каждого производства: от малого бизнеса до самых крупных предприятий.

Для начала разберемся, что понимается под снабжением. Снабжение - процесс, реализуемый организационной единицей, которая, будучи частью интегрированной цепи поставок, отвечает за приобретение всех материалов и услуг требуемого качества в необходимом количестве, в нужное время по наименьшей общей стоимости с сохранением должного уровня сервиса и за управление поставщиками, на основе чего организация получает конкурентное преимущество и реализует корпоративную стратегию[3-5].

Из вышесказанного стоить отметить главное: удовлетворение предприятия в получаемой им продукции. Как уже было отмечено, почти $84 \%$ всех предприятий мира не могут функционировать и оптимально заниматься своей деятельностью без поставляемых извне материалов, то есть прослеживается прямая зависимость от поставщиков. Поэтому те отделы предприятия, которые занимаются установлением контакта с другими предприятиями для обеспечения себя всеми необходимыми ресурсами, должны находить пути решения таких целей, как:

- Обеспечение надежности и непрерывности материального потока и сервисного потока (услуг);

- Поддержание и повышение качества процесса снабжения на основе модернизации и рационализации;

- Оптимизация затрат на снабжение;

- Формирование и управление базой поставщиков;

- Управление взаимоотношениями с поставщиками;

- Достижение гармоничных, продуктивных рабочих отношений с функциональными подразделениями организации, являющимися внутренними клиентами отдела снабжения[12].

На словах все может показаться просто: предприятие выделяет для себя определенных поставщиков, которые удовлетворяют предприятие по всем приведенным параметрам, устанавливают контакт, и после проведения переговоров, подписывают договора о сотрудничестве. Но, как подсказывает практика, все намного сложнее: невозможно удовлетворить себя всеми параметрами одновременно. Поэтому организация старается выделить для себя наиболее важное в зависимости от сложившейся ситуации: например, либо это время, либо затраты. К сожалению, даже выделяя для себя основное, которое хочешь удовлетворить, не всегда это удается в полной мере.

Автор предлагает свой поход для решения двух вышесказанных задач: обеспечение надежности и непрерывности материального потока и сервисного потока (услуг), а также управление взаимоотношениями с поставщиками.

Одной из проблем логистики снабжения является отсутствие самих материалов у поставщика, что влечет сбои на производстве у предприятия. Рассмотрим данную проблему на обычном примере. Допустим, компания по производству мобильной техники закупает экраны для устройств у поставщика. Но, когда подходит время для отправки следующей партии экранов на предприятие, компания - поставщик не имеет должного количества. Тем самым компания, производящая мобильную технику,не может продолжить производство и рискует потерять прибыль, а для нахождения нового поставщика нужно опять же время. Однако нужно отметить, что сейчас большинство 
предприятий имеют договоренность с другими компаниями, если такая ситуация возникает. Но чтобы эта система, состоящая из предприятия и поставщиков, работала безотказно, и все ресурсы были в срок у предприятия, стоит подумать об использовании современных информационных технологиях $[6,7]$ и о создании единого информационного пространства среди предприятия и всех поставщиков, которые связаны с этим предприятием с использованием современных концепций управления предпринимательскими организациями [12].

Что, в моем понимании, является единым информационным пространством в логистике снабжения? Для начала отмечу, что журнал «ПРЕСС СЛУЖБА»характеризует это, как совокупность объектов, вступающих друг с другом в информационное взаимодействие, а также сами технологии, обеспечивающие это взаимодействие[13].Данное определение вполне характеризует мое профессиональное мнение. Нужно ввести такие технологии в сферу логистики снабжения, чтобы обеспечивали бесперебойную передачу информации не только по линии поставщик предприятие, но и поставщик - поставщик. Это может быть и в виде печатной общей конференции, а также общая телефонная линия, по которой можно с легкостью связаться со всеми участниками данной замкнутой коммуникационной сети. В этой ситуации можно воспользоваться услугами логистического консалтинга и достижениям инновационных технологий в логистике[7,8].

Для этого немало важным критерием выступает взаимная осведомленность одного поставщика о существовании другого и наоборот, тем самым максимально предотвратить перебои в поставке товара. Для понимания моей мысли, приведу пример. Опять же возьмем компанию по производству телефонов, которая заказывает экраны у поставщика. К назначенной дате, поставщик не имеет нужного количества для отправки, тем самым ставит под угрозу производство компании. Но, если будет настроена определенная коммуникация между тремя звеньями (предприятие - поставщик №1 - поставщик №2) то заранее проинформированный поставщик №2 может подстроиться и оформить поставки своевременно на предприятие, одновременно проинформировав другое предприятие.

Исходя из вышесказанного, автор считает, что информационные технологии играют весомую роль в логистике снабжения. И если наладить новые технологии для коммуникации не только между поставщиком и предприятием, но и между поставщиками, можно добиться оптимального решения задач закупочной логистики.

$$
* * *
$$

1. Воронов В.И. Международная логистика (Электронный ресурс). Вестник университета (Государственный университет управления). 2014. с.700.

2. Воронов В.И., Воронов А.В., Ермаков А.А. Внешнеторговая статистика в развитии международного маркетинга и логистики. Маркетинг. 2014. № 1 (134). С. 90-96.

3. Логистика и управление цепями поставок. Теория и практика. Основы логистики. Аникин Б.А.; Родкина Т.А.; Волочиенко В.А.; Заичкин Н.И.; Межевов А.Д.; Федоров Л.С.; Вайн В.М.; Воронов В.И.; Водянова В.В.; Гапонова М.А.; Ермаков И.А.; Ефимова В.В.; Кравченко М.В.; Серова С.Ю.; Серышев Р.В.; Филиппов Е.Е.; Пузанова И.А.;Учирова М.Ю.; Рудая И.Л. Учебное пособие / Москва, 2014.

4. Логистика: тренинг и практикум. Аникин Б.А., Вайн В.М., Водянова В.В., Воронов В.И., Гапонова М.А., Ермаков И.А., Ефимова В.В., Заичкин Н.И., Кравченко М.В., Пузанова И.А., Родкина Т.А., Серова С.Ю., Серышев Р.В., Федоров Л.С. Учебное пособие / Москва, 2014.

5. Воронов В.И. Методологические основы формирования и развития региональной логистики: Монография. - Владивосток: Изд-во Дальневосточного Университета, 2003. - 316 с.

6. Воронов В.И., Лазарев В.А. Информационные технологии в коммерческой деятельности. Часть 1. Владивосток: Изд-во ВГУЭС, 2000 г.- 104 с.

7. Воронов В.И., Лазарев В.А. Информационные технологии в коммерческой деятельности. Часть 2. (учебное пособие). Владивосток: Изд-во ВГУЭС, 2002 г. -112 с.

8. Аникин Б.А., Воронов В.И. Развитие и взаимосвязь основных концепций управления предпринимательскими организациями. Транспорт: наука, техника, управление. 2006. № 4, с. 7-14. 
9. Воронов В.И. Методологические аспекты экономического обеспечения логистических систем управления. Вестник университета (Государственный университет управления). 2006. № 4. С. 11.

10. Воронов В.И., Пичейкина А.С. Основные аспекты логистического консалтинга. Вестник университета (Государственный университет управления). 2007. Т. 1. № 19. С 151-159.

11. Воронов В.И., Кривоносов Н.А. Савостьянок Г.Н., Кожанова В.В Инновационные технологии в логистике. Научно-аналитический журнал: «Инновации и инвестиции» № 4, 2015- стр. 2-4.

12. Логистика и управление цепями поставок. Теория и практика. Основные и обеспечивающие функциональные подсистемы логистики: учебник/под ред. Б.А. Аникина и Т.А. Родкиной. - Москва: Проспект, 2011. - 608 с.

13. Всероссийский специализированный журнал «ПРЕСС - СЛУЖБА» [Электронный ресурс] / Под ред. Т.А. Асланова - Электрон.журн. - М.: Издательский дом «Имидж - Медиа», [200?]. Режим доступа: http://www.press-service.ru/terms/143/, свободный.

\section{Кабанов Ф.О. \\ Исследование состояния и развития логистики водоснабжения мегаполисов}

\section{Государственный университет управления}

(Россия, Москва)

doi: $10.18411 / l j-31-10-2017-30$

idsp: 000001:lj-31-10-2017-30

\section{Аннотация}

В данной статье подробно рассмотрены наиболее актуальные проблемы, связанные с водоснабжением городов на сегодняшний день, а также на основе их анализа указаны некоторые предложения по их устранению.

Ключевые слова: Логистика, водоснабжение города, водопроводноканализационное производство, реконструкция систем водоснабжения.

Наличие воды и ее кругооборот в природе является основой всего живого, на Земном Шаре вода в основном соленая и морская. Многие государства мира испытывают дефицит пресной воды для населения, своей хозяйственной экономической и социальной деятельности, поэтому используют технические средства и конструкторско-инженерные решения для водоподготовки к использованию морских и сточных вод [1-3] и логистические подходы в организации и управлении водоснабжением чистых потоков и водоотведением загрязненных с последующей их максимально возможной очисткой и фильтрацией с учетом логистических методов и принципов [4,5].

К сожалению, большинство городов нашей страны в настоящее время сталкиваются с большим количество проблем, которые связаны с нормальным обеспечением жителей горячей и холодной водой, а также штатной работой канализационной сети. Для решения этих проблем необходимо внедрять современные концепции управления, в том числе и логистическую концепцию[6,7] в работу системы муниципального управления. В настоящее время водоснабжение города представляет собой сложную логистическую систему, которая должна обеспечивать необходимым количеством и нормальным качеством воды весь город круглосуточно и без серьезных перебоев. При этом, эта система не должна нарушать функционирование других систем, таких как метрополитен, электросеть, подземные парковки и множества других коммуникаций, которые преимущественно располагаются под землей.

Реконструкция систем водоснабжения является достаточно актуальной проблемой для любого города, поскольку достаточно сложно удерживать такую сложную и большую систему в идеальном состоянии. Большинство систем водоснабжения испытывают схожие проблемы, например, недостаток воды, плохое качество воды, ее потеря в результате утечек, которые зачастую происходят в результате критического износа 